\title{
Morbidly adherent placenta and cesarean section methods. A retrospective comparative multicentric study on two different skin and uterine incision
}

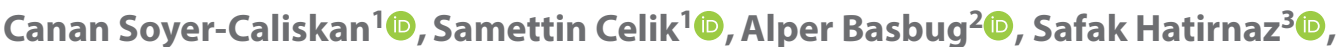

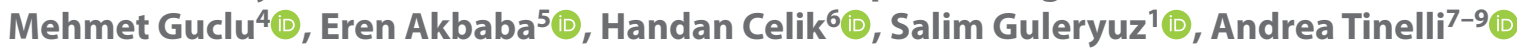 \\ ${ }^{1}$ Samsun Maternity Hospital, a Branch of Training and Research Hospital, Samsun, Turkey \\ ${ }^{2}$ Department of Obstetrics and Gynecology, School of Medicine, Düzce University, Düzce, Turkey \\ 3IVF Center, Medicana Samsun International Hospital, Samsun, Turkey \\ ${ }^{4}$ Marmara University, School of Medicine, Department of Obstetrics and Gynecology, Pendik Training and Research Hospital, \\ Istanbul, Turkey \\ ${ }^{5}$ Department of Obstetrics and Gynecology, School of Medicine, SitkıKocman University, Mugla, Turkey \\ ${ }^{6}$ Department of Obstetrics and Gynecology, Ondokuzmayıs University, Samsun, Turkey \\ ${ }^{7}$ Department of Obstetrics and Gynecology, "Veris delli Ponti" Hospital, Scorrano, Lecce, Italy \\ ${ }^{8}$ Division of Experimental Endoscopic Surgery, Imaging, Technology and Minimally Invasive Therapy, Vito Fazzi Hospital, \\ Lecce, Italy \\ ${ }^{9}$ Laboratory of Human Physiology, Phystech Bio Med School, Faculty of Biological \& Medical Physics, Moscow Institute \\ of Physics and Technology (State University), Dolgoprudny, Moscow Region, Russia
}

\begin{abstract}
Objectives: Morbidly adherent placenta (MAP) is one of leading causes of maternal mortality, with an increasing rate because of repeated cesarean sections (CS).

The primary objective of this study is to compare two techniques of skin and uterine incisions in patients with MAP, evaluating the maternal fetal impact of the two methods.

Retrospective multicentric cohort study.

Material and methods: A total of 116 women with MAP diagnosis were enrolled and divided in two groups. Group one, comprised of 81 patients, abdominal entry was performed by Pfannenstiel skin incision plus an upper transverse lower uterine segment (LUS) incision (transverse-transverse), which was 2-3 cm above the MAP border, with the uterus in the abdomen. In group two, comprised of 35 patients, abdominal entry was performed by an infra-umbilical midline abdominal incision, by vertical-vertical technique, and the pregnant uterus was incised by a midline incision (vertical) from the fundus till the border of the MAP.

Total surgery time, blood loss, blood product consumption, total hospital stay, cosmetic outcomes, and postoperative complications were investigated.

Results: Total time of surgery was significantly shorter in group $1(p<0.05)$. Intraoperative blood loss was higher in group 2. Difference between preoperative and postoperative $\mathrm{Hb}$ and Htc levels were $3.30 \pm 1.04$ and $12.99 \pm 5.07$ respectively $(p=0.012 ; p=0.033$ ). The use of erythrocyte suspension (ES), fresh frozen plasma (FFP), and cryoprecipitate and thrombocyte suspension (TS) were found to be significantly lower in patients of group 1than vertical-vertical group $(p=0.008$, $p=0.009, p=0.001, p=0.001$, respectively). There was no difference in terms of total length of hospital stay between groups. Conclusions: In a subgroup of patients diagnosed for MAP, the transverse-transverse incision resulted in less bleeding, less blood and blood product use, and had better cosmetic results than vertical-vertical incision. Moreover, the total time of surgery, crucial for MAP patients, seems to be shorter also in transverse-transverse incision than in vertical-vertical incision. Key words: morbidly adherent placenta; pfannenstiel incision; uterine incision; cesarean section; complications
\end{abstract}




\section{INTRODUCTION}

Morbidly adherent placenta (MAP) is an abnormal invasive placenta in which chorionic villi pass Nitabuch's layer [1-3]. In new obstetric nomenclature, the MAP was also called as" placenta creata spectrum" [4]. The defective or absent structure of decidua basalis and defective development of the fibrinoid layer are the possible pathological mechanisms [5].

Currently, there is an increasing number of MAP associated pregnancies in United States, with an average incidence of 1/731 cases and with 4504 estimated new annual cases, with an average 130 maternal mortalities for complications [6].

Increasing rates worldwide of cesarean section (CS) for delivery have become a major public health issue and the rates of placental insertion abnormalities have been rising accordingly. In fact, the MAP incidence is estimated on $1 / 533$ deliveries [7]. The MAP has become a leading cause of maternal mortality, especially in hospital settings without an experienced surgical team and blood banking [8]. Most women experienced MAP because of repeated CS [9].

There are three variants of MAP that are histologically classified according to the depth of the placental invasion. Placenta accreta is defined as the attachment of chorionic villi to the myometrium, placenta increta is the invasion of the myometrium by the villi, and placenta percreta is defined as the villous invasion beyond the myometrium, reaching the uterine serosa. Anyway, the MAP terminology is accepted for practical use [10].

Such a diagnosis is crucial in the antenatal period, to manage these patients because all women with MAP must be prepared as if they need elective cesarean hysterectomy. But considering future fertility and the possibility of primary repair, a conservative approach may be selected for those whose intraoperative evaluation is appropriate [11].

While vertical skin incision may favor eventual hypogastric artery ligation in cases of massive bleeding, anyway such procedure can also be managed through Pfannenstiel incision $[12,13]$.

This raised a surgical question: which type of skin and uterine incision, horizontal or vertical, could be better in the management of a MAP surgery?

The aim of this study is to compare Pfannenstiel skin incision and upper transverse uterine incision (transverse-transverse) to midline vertical skin incision and vertical uterine incision (vertical-vertical) evaluating their impact on maternal, fetal and surgical outcomes.

\section{MATERIAL AND METHODS}

Authors performed a retrospective multicentric cohort study between March 2012 and December 2018. This study was approved by the ethical committee of Marmara Uni- versity, School of Medicine, Turkey, with a grant number of 09.2019.253.

A total of 159 files of women who had obstetric surgery for MAP were investigated. Twenty-two patients with emergency MAP surgery were excluded from the study.

Ten women who had Pfannenstiel incisions and vertical uterine incisions and 11 women who had vertical skin incisions and upper transverse uterine incisions were also excluded from the study groups for the homogeneity of the study. The aim of the study was to investigate the impact of skin and uterine incision on maternal and fetal outcomes, total surgery time, blood loss, blood product consumption, length of hospital stay, cosmetic outcomes, and postoperative complications.

\section{Antenatal follow-up}

The pregnant women who were diagnosed, during pregnancy, for MAP were followed in the high-risk pregnancy units of the attending hospitals. All patients were scanned by ultrasound, clinical data were recorded and electively delivered at 34-35 weeks of gestation after MAP diagnosis during pregnancy.

The MAP diagnosis was performed during pregnancy surveillance, by the transabdominal ultrasound and color Doppler imaging, to verify the placental invasion and placental mapping. The diagnostic criteria for MAP were ultrasound findings of lacunar images more than three, an irregular bladder wall, increased irregular sub-placental vascularity, irregular myometrial vision, especially at the previous incision site, and loss of clear retro-placental space [14-16].

\section{Surgical technique and preoperative preparation}

All doctors involved in the investigation were skilled and performed all types of abdominal and uterine incisions. Before carrying out the CS, each patient had the diagnosis of placental localization (or placental topography), in order to decide where to incise the uterus. All patients were hospitalized at 34 weeks, and surgery for MAP was generally arranged at 34-35 weeks of gestation, under general anesthesia or spinal/epidural anesthesia, depending on patients' conditions. For all cesarean section, four units of erythrocyte suspension and four units of plasma were reserved in the blood bank before the surgery. Generally, before surgery, one course of antenatal corticosteroid was administered to the patients for fetal lung maturity.

\section{Vertical-vertical technique (Group 1)}

Bladder catheterization was performed in the operating theatre before the surgical procedure began in all patients. Following sterile cleansing and covering of the surgical field, abdominal entry was performed by an infra-um- 
bilical midline abdominal incision (vertical). The pregnant uterus was incised by a midline incision (vertical) from the fundus till the border of the MAP in order to remove the fetus safely. The placenta was gently detached from the uterine wall if possible, and if it was not removed, the placenta, membranes, and the umbilical cord were left in the uterine cavity and the uterus was sutured. After that, the uterine arteries were clamped above the ureteral crossing level and a cesarean hysterectomy was performed. Then the ligamentum ovarii propria were dissected, and the cardinal ligaments were rapidly clamped and sutured. Vascular structures around the bladder were cauterized and ligated. Then the bladder was mobilized fully away from the MAP field. The uterus was removed totally in hysterectomy cases. In cases where the uterus was preserved, the MAP field was resected, the defect was sutured by a continuous locking or figure of eight No. 1 Vicryl. A Bakri balloon was inserted and inflated after the procedure if needed. Following hemostasis, the vertically incised uterus was sutured carefully. The bladder was carefully examined for any injury and filled with 200-300 mL to check for any urinary leakage in cases where bladder injury was suspected. One or two silicone drains were inserted into the pouch of Douglas, abdominal layers were sutured and closed, and the surgical operation was finished. All interventions, blood products used, complications, and the total amount of blood loss were recorded. In cases where over five to six erythrocyte suspensions and six plasma extracts were transfused, four to six units of irradiated thrombocyte transfusion were recommended. According to the fibrinogen level, cryoprecipitate or fibrinogen ampules were used. Patients were followed with hourly hematocrit and coagulation factors until they were stabilized.

\section{Transverse-transverse technique (Group 2)}

In this technique, abdominal entry was performed by a lower abdominal transverse incision, namely a Pfannenstiel incision, and the uterus remained in the abdominal cavity. The fetus was removed from the upper uterine transverse incision, which was $2-3 \mathrm{~cm}$ above the MAP border. All procedures, concerning preservation of the uterus or hysterectomy and the protocol of blood product supplementation, are the same as the vertical-vertical technique.

Materials removed from the field of MAP or hysterectomy were evaluated for pathological diagnosis. Type of surgery, hemodynamic changes, blood loss during surgery, total time of surgery, and incisions, transfusions of blood products, perioperative complications, maternal complications, fetal complications, Apgar scores, type of anesthesia, bladder injury, and all other parameters concerning MAP surgery were recorded and included in the database Cesarean Hysterectomy.

\section{Statistical analysis}

The data in the study were analyzed using IBM SPSS Statistics for Windows v 21.0 (IBM Corp, Armonk, NY). In the tables, the quantitative data are presented as the mean \pm SD and median (minimum-maximum) values, and the categorical data as number ( $\mathrm{n}$ ) and percentage (\%). Student's $t$ test and the Mann-Whitney $U$ test were used to compare the independent groups, and Pearson's chi-square test and Fisher's exact test to compare the categorical variables. Data were determined at the $95 \%$ confidence level, and a $p$ value $<0.05$ was accepted as statistically significant.

\section{RESULTS}

A total of 159 women who had a MAP diagnosis were evaluated. Twenty-two women with emergency cesarean section, 10 women with transverse skin and vertical uterine incision and 11 women with vertical skin and transverse uterine incision were excluded. Then, a total of 116 women were included in this study $(73 \%$ of the whole investigated women). Thirty-five women (30.2\%) who had surgery with vertical-vertical incisions included in Group 1, while 81 (69.8\%) women who had surgery with transverse-transverse incisions were included in Group 2 for comparison. There was no difference between the groups in terms of age, gravidity, or body mass index. There was a statistically significant difference between the groups in terms of the number of previous cesarean sections $(p=0.014)$. The mean gestational weeks of the patient were $34.23 \pm 2.82$ and $35.46 \pm 1.98$ in Group 1 and Group 2, respectively $(p=0.024)$. It was found that the total time of surgery was shorter in the transverse-transverse group than in the vertical-vertical group, which was statistically significant $(p<0.05)$. However, there was no difference in terms of total length of hospital stay between groups (Tab. 1). While preoperative $\mathrm{Hb}$ and $\mathrm{Htc}$ levels were not different between the groups, postoperative $\mathrm{Hb}$ and $\mathrm{Htc}$ levels were significantly lower in vertical-vertical incision group than transverse-transverse group $(7.66 \pm 0.75 ; 8.21 \pm 0.98$, $\mathrm{p}=0.004$ for $\mathrm{Hb} ; 21.76 \pm 3.19 ; 23.15 \pm 3.68 \mathrm{p}=0.044$ for $\mathrm{Htc}$ respectively). Intraoperative blood loss was higher in vertical-vertical incision group. Difference between preoperative and postoperative $\mathrm{Hb}$ and $\mathrm{Htc}$ levels were $3.30 \pm 1.04$ and $12.99 \pm 5.07$ respectively $(p=0.012$; $p=0.033$ ) (Tab. 2). Bladder injury was found to be significantly lower in the transverse-transverse group (13 patients, $37.1 \%$ in vertical-vertical group versus 9 patients, $11.1 \%$ in transverse-transverse group $(p=0.001)$ (Tab. 3). The use of erythrocyte suspension (ES), fresh frozen plasma (FFP), and cryoprecipitate and thrombocyte suspension (TS) during surgery was found to be significantly lower in patients with transverse incisions $(p=0.008, p=0.009, p=0.001$, $p=0.001$, respectively) (Tab. 4). 
Table 1. Demographic characteristics, operative time and type of anesthesia

\begin{tabular}{|c|c|c|c|}
\hline & $\begin{array}{l}\text { Group } 1 \\
\text { (vertical - } \\
\text { vertical) } \\
(\mathrm{n}=35) \\
\text { (Mean } \pm \text { SD) }\end{array}$ & $\begin{array}{l}\text { Group } 2 \\
\text { (transverse - } \\
\text { transverse) } \\
\text { ( } n=81 \text { ) } \\
\text { (Mean } \pm \text { SD) }\end{array}$ & $p$ value \\
\hline Age [years] & $32.14 \pm 4.57$ & $30.48 \pm 4.48$ & $0.071^{b}$ \\
\hline Gravida (n) & $3(2-7)$ & $3(2-5)$ & $0.352^{a}$ \\
\hline Previous C/S (n) & $2(1-6)$ & $2(1-4)$ & $0.014^{* a}$ \\
\hline $\begin{array}{l}\text { Gestational Weeks } \\
\text { at the time delivery } \\
\text { [week] }\end{array}$ & $34.23 \pm 2.82$ & $35.46 \pm 1.98$ & $0.024^{* b}$ \\
\hline $\begin{array}{l}\mathrm{BMI} \\
{\left[\mathrm{kg} / \mathrm{m}^{2}\right]}\end{array}$ & $28.94 \pm 3.17$ & $29.43 \pm 2.24$ & $0.309^{b}$ \\
\hline $\begin{array}{l}\text { Total time of surgery } \\
\text { [min] }\end{array}$ & $100.44 \pm 18.35$ & $91.23 \pm 16.53$ & $0.010^{* b}$ \\
\hline $\begin{array}{l}\text { Length of hospital } \\
\text { stay [days] }\end{array}$ & $5(3-8)$ & $4(3-8)$ & $0.111^{a}$ \\
\hline $\begin{array}{l}\text { Type of Anesthesia } \\
\text { General } \\
\text { Spinal }\end{array}$ & $\begin{array}{l}28(80 \%) \\
7(20 \%)\end{array}$ & $\begin{array}{l}43(53.1 \%) \\
38(46.9 \%)\end{array}$ & $\begin{array}{l}0.001^{* c} \\
0.001^{* c}\end{array}$ \\
\hline
\end{tabular}

Values are stated as mean $\pm S D$, median (minimum-maximum) and percentage (\%); ${ }^{a}$ Mann-Whitney U test; ${ }^{b}$ Student's t test; ${ }^{\circ}$ Chi-square test; ${ }^{*} \mathrm{p}<0.05$ indicates statistical significance; SD — standard deviation; BMI - body mass index; $\mathrm{C} / \mathrm{S}$ - cesearen

Table 2. Changes in laboratory parameters

\begin{tabular}{|c|c|c|c|}
\hline & $\begin{array}{l}\text { Vertical - } \\
\text { vertical } \\
(n=35) \\
\text { (Mean } \pm \text { SD) }\end{array}$ & $\begin{array}{l}\text { Transverse - } \\
\text { transverse } \\
(n=81) \\
(\text { Mean } \pm \text { SD) }\end{array}$ & $p$ value \\
\hline $\begin{array}{l}\mathrm{Hb}[\mathrm{g} / \mathrm{dL}] \\
\text { Pre-op } \\
\text { Post-op } \\
\text { Difference }\end{array}$ & $\begin{array}{l}10.96 \pm 0.98 \\
7.66 \pm 0.75 \\
3.30 \pm 1.04\end{array}$ & $\begin{array}{l}10.98 \pm 0.76 \\
8.21 \pm 0.98 \\
2.77 \pm 1.02\end{array}$ & $\begin{array}{l}0.907^{b} \\
0.004^{* b} \\
0.012^{* b}\end{array}$ \\
\hline $\begin{array}{l}\text { Htc [\%] } \\
\text { Pre-op } \\
\text { Post-op } \\
\text { Difference }\end{array}$ & $\begin{array}{l}34.76 \pm 4.46 \\
21.76 \pm 3.19 \\
12.99 \pm 5.07\end{array}$ & $\begin{array}{l}33.99 \pm 4.64 \\
23.15 \pm 3.68 \\
10.84 \pm 4.43\end{array}$ & $\begin{array}{l}0.410^{b} \\
0.044^{* b} \\
0.033^{* b}\end{array}$ \\
\hline $\begin{array}{l}\text { Platelet [103/mL] } \\
\text { Pre-op } \\
\text { Post-op } \\
\text { Difference }\end{array}$ & $\begin{array}{l}250.11 \pm 72.37 \\
118.20 \pm 17.98 \\
131.91 \pm 73.02\end{array}$ & $\begin{array}{l}278.54 \pm 59.88 \\
134.54 \pm 28.17 \\
144.04 \pm 71.33\end{array}$ & $\begin{array}{l}0.056^{b} \\
0.002^{* b} \\
0.407^{b}\end{array}$ \\
\hline $\begin{array}{l}\text { Fibrinojen }[\mathrm{mg} / \mathrm{dL}] \\
\text { Pre-op } \\
\text { Post-op } \\
\text { Difference }\end{array}$ & $\begin{array}{l}275.57 \pm 68.11 \\
130.77 \pm 37.35 \\
140.80 \pm 70.05\end{array}$ & $\begin{array}{l}289.86 \pm 41.92 \\
149.88 \pm 43.81 \\
144.98 \pm 59.85\end{array}$ & $\begin{array}{l}0.207^{b} \\
0.026^{* b} \\
0.473^{b}\end{array}$ \\
\hline $\begin{array}{l}\text { INR (n) } \\
\text { Pre-op } \\
\text { Post-op } \\
\text { Difference }\end{array}$ & $\begin{array}{l}1.21 \pm 0.10 \\
1.70 \pm 0.65 \\
0.48 \pm 0.03\end{array}$ & $\begin{array}{l}1.21 \pm 10 \\
1.31 \pm 0.31 \\
0.11 \pm 0.09\end{array}$ & $\begin{array}{l}0.891^{b} \\
0.001^{* b} \\
0.001^{* b}\end{array}$ \\
\hline
\end{tabular}

Values are stated as mean $\pm \mathrm{SD} ;$ 'bStudent's t test; ${ }^{*} \mathrm{p}<0.05$ indicates statistical significance; $\mathrm{SD}$ - standard deviation; $\mathrm{Hb}$ - hemoglobin; $\mathrm{Htc}$ - hematocrit; INR - international normalized ratio

\begin{tabular}{|c|c|c|c|}
\hline & $\begin{array}{l}\text { Vertical - } \\
\text { vertical } \\
(\mathbf{n}=35)\end{array}$ & $\begin{array}{l}\text { Transverse - } \\
\text { transverse } \\
(\mathbf{n = 8 1})\end{array}$ & p value \\
\hline Bladder injury (n) & $13(37.1 \%)$ & $9(11.1 \%)$ & $0.001^{c}$ \\
\hline Hysterectomy (n) & $29(82.9 \%)$ & $66(81.5 \%)$ & $0.860^{d}$ \\
\hline Re-bleeding ( $\mathrm{n}$ ) & $2(5.7 \%)$ & 0 & $0.030^{d}$ \\
\hline Postpartum fever (n) & $3(8.6 \%)$ & $5(6.2 \%)$ & $0.640^{d}$ \\
\hline $\begin{array}{l}\text { Deep vein } \\
\text { thrombophlebitis or } \\
\text { pulmonary embolism (n) }\end{array}$ & $2(5.7 \%)$ & $1(1.2 \%)$ & $0.163^{d}$ \\
\hline Wound infection (n) & $3(8.6 \%)$ & $6(3.7 \%)$ & $0.277^{d}$ \\
\hline Sepsis (n) & 0 & 0 & N.A \\
\hline Pelvic abcess (n) & 0 & $1(1.2 \%)$ & $0.509^{d}$ \\
\hline
\end{tabular}

Values are stated as percentage (\%); ' ${ }^{C}$ Chi-square test; ${ }^{\mathrm{d}}$ Fisher's exact test; ${ }^{*} \mathrm{p}<0.05$ indicates statistical significance; N.A — Not Applicable

\begin{tabular}{l|l|l|l|l|}
\hline Table 4. Blood product transfusion \\
\hline & $\begin{array}{l}\text { Vertical - } \\
\text { vertical } \\
(\mathbf{n}=\mathbf{3 5})\end{array}$ & $\begin{array}{l}\text { Transverse - } \\
\text { transverse } \\
(\mathbf{n = 8 1 )}\end{array}$ & p value \\
\hline Erytrocytesuspention & $4(4-10)$ & $3(3-10)$ & $0.008^{* a}$ \\
\hline FFP & $4(0-8)$ & $2(0-8)$ & $0.009^{* a}$ \\
\hline Cryoprecipitate & $0(0-20)$ & $0(0-10)$ & $0.001^{* a}$ \\
\hline Thrombocyte & $0(0-4)$ & $0(0-3)$ & $0.001^{* a}$
\end{tabular}

Values are stated as median (minimum-maximum); ${ }^{\mathrm{a} M a n n-W h i t n e y ~} \mathrm{U}$ test; ${ }^{*} \mathrm{p}<0.05$ indicates statistical significance; FFP — fresh frozen plasma

\section{DISCUSSION}

There is no consensus on the standard type of surgery performed in MAP cases, with the increasing efforts for training surgeons, increasing number of centers, and increased success rates with reducing complications rate. Moreover, in MAP patients with anteriorly located placenta, it becomes very difficult to decide about the vertical or horizontal incisions. Incising the uterus from the lower uterine segment may be detrimental because of severe bleeding, and the surgery may have mortal outcomes.

In the MAP management, there are some important variables that may affect the selection criteria of the type of surgical procedure, including demand of continuation of potential for delivery, the experience of the surgical team, surgical skills, the degree of the health facility and the presence of blood banking, and maternal preferences [5]. Moreover, in some cases it could be difficult to remove an enlarged uterus through transverse skin incision; this could cause a delay in the removal of the baby and prolong the total 
surgery time. In such a circumstance, precesarean amniotic fluid aspiration can reduce the uterine size and make ease the surgical procedure [6].

Our results showed that the transverse incisions for both skin and the uterus in case of MAP has fewer complications, reduces the time of the surgery, necessitates of less blood product and cosmetically more acceptable than vertical incisions. One of the MAP problems is the detachment of the bladder from the uterus. Surgeon, to preserve bladder vascularization, should incise rather transversally to preserve the bladder without major bleeding.

The management of MAP by using proactive peripartum multidisciplinary approach (PAMA) was effective in reducing urgent deliveries and related significant complications, without increasing rates of cesarean hysterectomy [17].

In case of emergency conditions, it should be mandatory to shorten the delivery time also by using the vertical skin and uterine incisions [18].

In a study conducted by Wylie et al., skin incisions were compared in emergency CS due to abruption, and hemorrhage due to previa, and they reported that even though transverse skin incisions prolong the surgical time by 1-2 minutes, there was no statistical difference for the surgical outcomes in the two skin incision types. Authors reported that vertical skin incisions may increase postpartum endometritis, and the neonatal outcomes were not superior in the vertical incision group, even if most of the CS were performed through suprapubic transverse skin incisions together with upper transverse uterine incisions. So, even in emergency surgery, suprapubic transverse incision may be safely selected in emergency CS [19].

Anyway, whatever technique is preferred, the most important thing is to avoid excessive maternal bleeding and eventual coagulopathy [20]. Maternal preferences and the future fertility expectation in such cases drive the surgical team to preserve the uterus by two methods. The first technique is by leaving the placenta in its place (not routinely recommended) and the second is by incising the uterus from the upper area (2-3 cm above the percreta line), partially removing the lower uterine segment and preserving the uterus $[20,21]$.

In a study [20], after controlled ligation of the bleeding vessels in the placental bed or segmental resection of the lower uterine segment (LUS), surgeons re-sutured the LUS to preserve uterus. In another study [21], surgeons performed hysterotomy by upper transverse incision without increase the hysterectomy rates, with no substantial difference in comparison to vertical uterine incision.

Moreover, basing on the uterine rupture rates very low after myomectomies performed by transverse uterine incisions [22], the upper transverse uterine incisions in MAP surgery rather than vertical uterine incisions should be a safe approach for uterine rupture reducing.

Our proposed uterine incision technique is similar to the Kotsuji et al. [9], method, in which it is recommend a fundal transverse incision for the fetal removal, but to do this, it is necessary a longitudinal laparotomy. On the contrary, in our transversal laparotomy, it is preferred to use a transverse incision below the fundal region and just $2-3 \mathrm{~cm}$ above the percreta line. That is the reason why suprapubic transverse skin incisions make it possible the fetal delivery without difficulty.

The strengths of our study are that we are first comparing both skin and uterine incisions and their surgical outcomes, performed by surgeons skilled in both incisions.

The limitations of the study were the retrospective investigation, performed only in hospital settings with a blood bank and by different surgeons. Moreover, we had difficulty in patients' homogenization.

\section{CONCLUSIONS}

As an alternative to the longitudinal skin and uterine incision, the transverse suprapubic skin incision and upper transverse uterine incision during CS can be safely performed in selected patients with MAP diagnosis, without increasing the hysterectomy rates. These transversal incisions may decrease the blood product use and total time of the surgery. Further prospective studies with large sample sizes are warranted to clarify the advantages and disadvantages of this surgical technique.

\section{Acknowledgement}

None.

\section{Funding}

No funding for this study.

\section{Financial disclosure}

Nothing to disclose financially.

Conflict of interest

Authors declare no conflict of interest.

\section{REFERENCES}

1. Groom K, Paterson-Brown S. Placenta praevia and placenta praevia accreta - a review of aetiology, diagnosis and management. Fetal and Maternal Medicine Review. 2001; 12(1): 41-66, doi: 10.1017/s0965539501000134.

2. Silver RM, Barbour KD. Placenta accreta spectrum: accreta, increta, and percreta. Obstet Gynecol Clin North Am. 2015; 42(2): 381-402, doi: 10.1016/j.ogc.2015.01.014, indexed in Pubmed: 26002174.

3. Comstock $\mathrm{CH}$. Antenatal diagnosis of placenta accreta: a review. UItrasound Obstet Gynecol. 2005; 26(1): 89-96, doi: 10.1002/uog.1926, indexed in Pubmed: 15971281.

4. Jauniaux E, Ayres-de-Campos D. FIGO Placenta Accreta Diagnosis and Management Expert Consensus Panel. FIGO consensus guidelines 
on placenta accreta spectrum disorders: Introduction. Int J Gynaecol Obstet. 2018; 140(3): 261-264, doi: 10.1002/ijgo.12406, indexed in Pubmed: 29405322.

5. Polat I, Yücel B, Gedikbasi A, et al. The effectiveness of double incision technique in uterus preserving surgery for placenta percreta. BMC Pregnancy Childbirth. 2017; 17(1): 129, doi: 10.1186/s12884-017-1262-3, indexed in Pubmed: 28449642.

6. Braun $\mathrm{T}$, Weizsäcker $\mathrm{K}$, Muallem $\mathrm{MZ}$, et al. Abnormally invasive placenta (AIP): pre-cesarean amnion drainage to facilitate exteriorization of the gravid uterus through a transverse skin incision. J Perinat Med. 2018; 47(1): 12-15, doi: 10.1515/jpm-2017-0388, indexed in Pubmed: 29870394.

7. Garmi G, Salim R. Epidemiology, Etiology, Diagnosis, and Management of Placenta Accreta. Obstetrics and Gynecology International. 2012; 2012: 1-7, doi: 10.1155/2012/873929.

8. Polat I, Alkis I, Sahbaz A, et al. Diagnosis and management of cesarean scar pregnancy. Clin Exp Obstet Gynecol. 2012; 39(3): 365-368, indexed in Pubmed: 23157046.

9. Fujiwara-Arikura S, Nishijima K, Tamamura $C$, et al. Transverse uterine fundal incision for placenta praevia with accreta, involving the entire anterior uterine wall: a case series. BJOG. 2013; 120(9): 1144-1149, doi: 10.1111/1471-0528.12252, indexed in Pubmed: 23639121.

10. Belfort MA, Shamshirsaz AA, Fox KA. The diagnosis and management of morbidly adherent placenta. Semin Perinatol. 2018; 42(1): 49-58, doi: 10.1053/j.semperi.2017.11.009, indexed in Pubmed: 29195695.

11. Palacios Jaraquemada JM, Pesaresi M, Nassif JC, et al. Anterior placenta percreta: surgical approach, hemostasis and uterine repair. Acta Obstet Gynecol Scand. 2004; 83(8): 738-744, doi: 10.1111/j.0001-6349.2004.00 517.x, indexed in Pubmed: 15255846.

12. Melekoglu R, Celik E, Eraslan S, et al. Conservative management of post-partum hemorrhage secondary to placenta previa-accerta with hypogastric artery ligation and endo-uterine hemostatic suture. J ObstetGynecol Res. 2017; 43(2): 265-271.

13. Zuckerwise LC, Craig AM, Newton JM, et al. Outcomes following a clinical algorithm allowing for delayed hysterectomy in the management of severe placenta accreta spectrum. Am J Obstet Gynecol. 2020; 222(2): 179.e1-179.e9, doi: 10.1016/j.ajog.2019.08.035, indexed in Pubmed: 31469990.

14. Lopes ES, Feitosa FE, Brazil AV, et al. Assessment of Sensitivity and Specificity of Ultrasound and Magnetic Resonance Imaging in the Diagnosis of Placenta Accreta. Rev Bras Ginecol Obstet. 2019; 41(1): 17-23, doi: 10.1055/s-0038-1675803, indexed in Pubmed: 30428490.

15. Wang $Y$, Gao $Y$, Zhao $Y$, et al. Ultrasonographic diagnosis of severe placental invasion. J Obstet Gynaecol Res. 2018; 44(3): 448-455, doi: 10.1111/jog.13531, indexed in Pubmed: 29271032.

16. Finberg $\mathrm{HJ}$, Williams JW. Placenta accreta: prospective sonographic diagnosis in patients with placenta previa and prior cesarean section. J Ultrasound Med. 1992; 11(7): 333-343, doi: 10.7863/jum.1992.11.7.333, indexed in Pubmed: 1522623.

17. Stanleigh J, Michaeli J, Armon S, et al. Maternal and neonatal outcomes following a proactive peripartum multidisciplinary management protocol for placenta creta spectrum as compared to the urgent delivery. Eur J Obstet Gynecol Reprod Biol. 2019; 237: 139-144, doi: 10.1016/j. ejogrb.2019.04.032, indexed in Pubmed: 31039488.

18. Palacios-Jaraquemada JM. Efficacy of surgical techniques to control obstetric hemorrhage: analysis of 539 cases. Acta Obstet Gynecol Scand. 2011;90(9): 1036-1042, doi: 10.1111/j.1600-0412.2011.01176.x, indexed in Pubmed: 21564024.

19. Wylie BJ, GilbertS, Landon $M B$, et al. Eunice Kennedy Shriver National Institute ofChild Health and Human Development (NICHD) Maternal-Fetal Medicine Units Network (MFMU). Comparison of transverse and vertical skin incision for emergency cesarean delivery. Obstet Gynecol. 2010; 115(6): 1134-1140, doi: 10.1097/AOG.0b013e3181df937f, indexed in Pubmed: 20502282.

20. Palacios-Jaraquemada JM. Caesarean section in cases of placenta praevia and accreta. Best Pract Res Clin Obstet Gynaecol. 2013; 27(2): 221-232, doi: 10.1016/j.bpobgyn.2012.10.003, indexed in Pubmed: 23127895.

21. Kilicci C, Ozkaya E, Eser A, et al. Planned cesarean hysterectomy versus modified form of segmental resection in patients with placenta percreta. J Matern Fetal Neonatal Med. 2017; 31(22): 2935-2940, doi: 10.1080/14767058.2017.1359535.

22. Igarashi M. Value of Myomectomy in the Treatment of Infertility. Fertil Steril. 1993; 59(6): 1331-1332, doi: 10.1016/s0015-0282(16)56003-8. 